\title{
SHOULD ANIMAL WELFARE BE INCLUDED IN EDUCATIONAL PROGRAMS? ATTITUDES OF SECONDARY AND UNIVERSITY STUDENTS FROM EIGHT EU COUNTRIES.
}

\author{
Niloofar Pejman $^{\mathrm{a} *}$, Zein Kallas ${ }^{\mathrm{b} *}$, Lourdes Reig ${ }^{\mathrm{b}}$, Antonio Velarde ${ }^{\mathrm{c}}$, María Moreno ${ }^{\mathrm{c}}$, Diego \\ Magnani $^{c}$, Vicky Protopapadaki ${ }^{\mathrm{c}}$, Vytautas Ribikauskas $^{\mathrm{d}}$, Daiva Ribikauskiene் $\dot{e}^{\mathrm{e}}$, Antoni Dalmau ${ }^{\mathrm{c}}$

\begin{abstract}
${ }^{a}$ Institute for Research in Sustainability Science and Technology (IS-UPC), Polytechnic University of Catalonia, (Barcelona, niloofar.pejman@upc.edu). ${ }^{b}$ Centre for Agro-food Economy and Development, CREDA-UPC-IRTA, (Castelldefels, zein.kallas@upc.edu,lourdes.reig@upc.edu). 'Institute of Agrifood Research and TechnologyIRTA.AnimalWelfareSubprogram,(Monells,antonio.velarde@irta.cat,m.moreno@faada.org,diegomag18 @yahoo.it,vickyproto@hotmail.com,antoni.dalmau@irta.cat). ${ }^{d}$ Veterinary Academy,_Lithuanian University of Health Sciences(Kaunas, Lithuania,Vytautas.Ribikauskas@lsmuni.lt). ${ }^{e}$ Kauno Kolegija I University of Applied Sciences, Kaunas, Lithuania, daiva.ribikauskiene@go.kauko.lt).
\end{abstract}

\begin{abstract}
Animal Welfare educational programs aim to promote positive attitudes of future generations towards animal production systems. This study investigated whether secondary and university students in the majors that are not related to AW teaching believe that this concept should be included also in their educational programs. The determinant factors affecting students' attitudes towards such a decision were analysed. This research has focused on eight European countries (Spain, the United Kingdom, Poland, Greece, Lithuania, Romania, Italy, and Sweden) targeting 3,881 respondents composed of 1,952 secondary and 1,929 university students. Results showed that female university students with a level of subjective and objective knowledge on AW and who required more restrictive AW regulations, gave support to include the concept in their educational programs. However, Students who support medical experiments that use animals to improve human health were less likely to accept AW education. Students in Italy compared to those in Sweden were prone to support AW educational programs. Results highlight the importance of teaching the AW concept as a comprehensive teaching tool at universities and schools' programs as it may constitute a starting point for a more sustainable society toward improving animal living conditions, mainly in the Mediterranean countries in secondary schools.
\end{abstract}

Keywords: Animal welfare, educational programs,secondary school,university,European Union.

\section{Introduction}

In parallel with growing public attitudes toward the current level of animal welfare (hereafter, AW) (Weijden \& Verhave, 2013), the education system becomes an important pathway to enhance adolescent's awareness regarding farm animal's life. In the majority of the schools and universities, AW aspects are not formally included in general education curricula as also highlighted by Ronto et al. (2016). In general, AW education can be considered as either a private good or a public good (Langford, 2006). On one hand, if AW education is considered as a private good, students as consumers could affect all stages of a farm animal's life, through influence on the current and future purchasing of animal-based products that ensure better AW .On the other hand, if AW education is considered as a public good, student as citizens are educated to become a member of society to further communal gain, leading to positive attitudes toward the animal's life.

\section{Materials and Methods}

2.1. Data Collection, questionnaire, and sample size

To reach the above-mentioned objectives, the European Commission launched the research project EDUCAWEL dealing with education and information activities, including various aspects of European culture.A semi-structured questionnaire was distributed and analyzed in eight European Union (EU) countries including Mediterranean European countries (Greece, Italy, and Spain), Central European countries (Romania, Poland, and Lithuania), and Northern European countries (the United Kingdom and Sweden).

\subsection{Factors affecting students' opinions to include $A W$ in their curricula}

To assess students' opinions towards AW and its inclusion in their educational program, they were directly asked if AW concept and issues should be taught and included in their curriculum. A binomial logistic regression (logit model) was applied to understand the factor affecting the student's decision and opinion. The response variables $(\mathrm{Y})$ is defined as 1 if a respondent answers "yes" for implementing AW in the curriculum of school and university and a value of 0 if a respondent answers "no". The independent variables were presented according to the following categories: The independent variables were those 
previously noted as potentially relevant factors and were presented according to the following categories: (1)Socio-economic variables; (2) The driven definition of AW concept ;(3) Students' Subjective and objective knowledge level towards AW;(4) Students' concerns regarding the welfare of farmed animals species; (5) Students' opinions regarding the current level of AW regulation in their country;(6) Respondent role (i.e., Secondary \& University students); and (7) Students' opinions towards the use of animals in different activities(8) Students' opinions if AW regulations should be more restrictive;and (9)Country of residency

\subsubsection{What Animal Welfare concept means to students?}

Students were asked directly "What do you think Animal Welfare means?" The most common expressions extracted were described into the following AW aspects: 1) outdoor access, 2) housing conditions, 3) suffering, 4) healthy conditions, 5) stress, 6) emotions 7) behavior 8) feeding and 9) happiness.

\subsubsection{Students' concerns regarding the welfare of farmed animals' species}

Students' concerns regarding the AW of different animal species was assessed by using an 11 points Likerttype scale ranging from 0 (not worried at all) to 10 (completely worried).

\subsubsection{Students' opinions regarding animals use in human activities}

Students were asked about their opinions regarding the alternative uses of animals using an 11 points Likerttype scale ranging from 0 (absolutely disagree) to 10 (absolutely agree).

\subsection{Students' subjective and objective knowledge towards animal welfare regulations}

Students' subjective knowledge was assessed by using an 11-point Likert-type scale ranging from 0 (Not informed at all) to 10 (have high knowledge). The objective knowledge was measured by asking respondents to identify from a group of 13 proposed statements on AW regulations that only some of them (8 statements) are currently regulated in a common policy framework at the EU level.

\section{Results}

3.1. What does Animal Welfare mean for students?

The most important aspect relating to the understanding of the AW concept was the clean housing and healthy environment for animals for the students from the Central European countries, United Kingdom, and Sweden as Northern European country. The most important aspect in Greece, Spain, and Italy was the outdoor conditions, medical treatment and, avoid pain and suffering, respectively.

\subsection{Students' concerns regarding the Animal Welfare of the farmed animals}

Secondary students in the Mediterranean countries, Central European countries, and the United Kingdom exhibited greater concern regarding AW than university students.Also, students assigned higher levels of concern for pigs, milk cows, and broilers than rabbits, goats, and laying hens.

\subsection{Opinions of secondary and university students towards animals' use alternatives}

The university students assigned the highest overall agreement score to kill animals when they are seriously injured or ill. On the other hand, the highest agreement score for secondary students was for animal uses in research experiments. The lowest agreement level for secondary and university students was found for the use of animals for cosmetic testing and painful sociocultural traditions.

\subsection{Level of Subjective and Objective knowledge of Animal Welfare}

Students in the Mediterranean countries, as well as students in Romania, believe that they are less informed compared to Northern European as well as central European countries. Students in Lithuania showed the highest value of subjective knowledge and the lowest value was found in Greece.Analyzing the objective knowledge level,our results showed that secondary and university students exhibited low objective knowledge regarding the current AW.

\subsection{Factors affecting students' opinions if $A W$ should be included in their educational programs}

A logit model was applied to analyze determinants factors affecting respondents' decisions to support educational programs in secondary and university curriculum. The descriptive results (Figure 1 and 2) show that both secondary and university students are more likely to accept AW to be included in their educational programs as was highlighted also by Sandgren et al. (2019). However, the results show that university students exhibited a greater interest in the education of AW in almost all countries compared to secondary students except for the UK. This may be related to the organization of the Royal Society for the Prevention of Cruelty to Animals (RSPCA) within universities and college curricula in England which is dedicated to enhancing student's attitudes to care for and respect animals. 
Figure 1. Should Animal welfare issues be included in your educational programs? (Secondary Students)

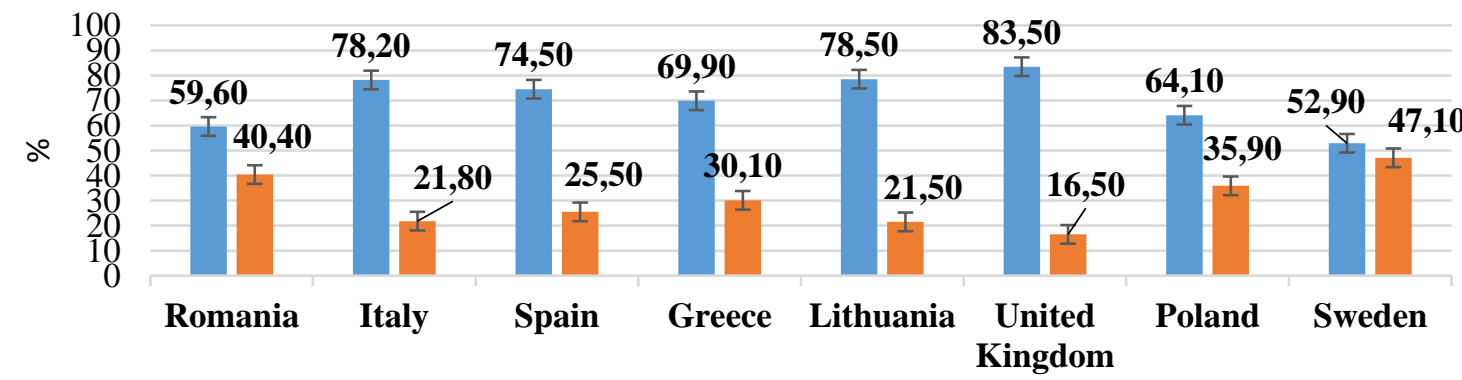

Yes\% $\quad$ No\%

Figure 2.Should Animal welfare issues be included in your educational programs? (University Students)

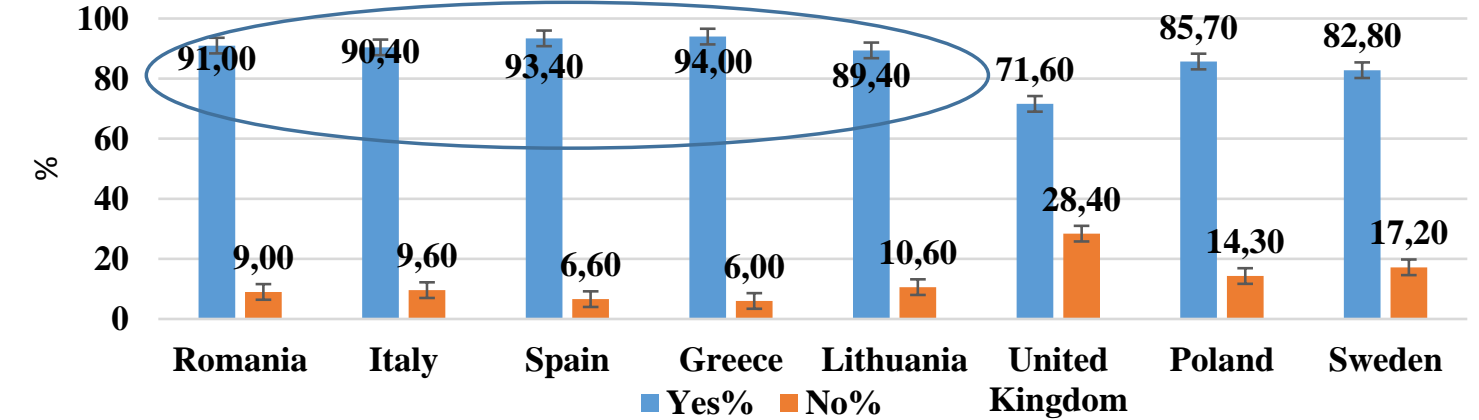

The dependent variable was codified as 1 for the "Yes" answers and 0 for the "no". The model was estimated on the pooled dataset by including a dummy variable for the respondent types (1 for university students and 0 for secondary one). Additional dummy variables were included representing each country. The results are shown in Table 1 . As can be seen, a satisfactory rate (78.9\%) of correct predictions was obtained.

Table 1. Factors affecting the acceptance to include $A W$ in the students' educational programs

\begin{tabular}{lccc}
\hline & B & Sig. & Exp(B) \\
\hline $\begin{array}{l}\text { Students' type } \\
\text { (University students=1, School students=0) }\end{array}$ & 1,219 & 0.000 & 3.385 \\
$\begin{array}{l}\text { Subjective Knowledge level about AW? } \\
\text { (0 non informed to 10 very informed) }\end{array}$ & 0.007 & 0.000 & 1.007 \\
$\begin{array}{l}\text { Objective Knowledge level } \\
\text { (The percentage of correct answer of respondents) }\end{array}$ & 0.005 & 0.038 & 1.005 \\
$\begin{array}{l}\text { Concerns regarding the AW of beef cattle for meat production } \\
\text { (0= I am not worried to 10= I am completely worried). }\end{array}$ & 0.057 & 0.001 & 1.058 \\
$\begin{array}{l}\text { Concerns regarding the AW of Pigs for meat production } \\
\text { (0= I am not worried to 10= I am completely worried). }\end{array}$ & 0.034 & 0.038 & 1.035 \\
$\begin{array}{l}\text { Concerns regarding the AW of Laboratory animals } \\
\text { (0= I am not worried to 10= I am completely worried). }\end{array}$ & 0.079 & 0.000 & 1.082 \\
$\begin{array}{l}\text { Students' opinions if AW regulations should be more restrictive } \\
\text { (1=Yes, 0=No) }\end{array}$ & 0.538 & 0.000 & 1.69 \\
$\begin{array}{l}\text { Italy (1= Italy, 0= Others) } \\
\text { Sweden (1 = Sweden, 0 = Others) }\end{array}$ & 0.343 & 0.014 & 1.409 \\
$\begin{array}{l}\text { Do you agree that medical experiments use animals to improve human } \\
\text { health? (0=absolutely disagree to 10 totally agree) } \\
\text { Gender (1= female 0= male)) }\end{array}$ & -0.692 & 0.000 & 0.501 \\
\hline $\begin{array}{l}\text { Correct classification } \\
\text { Hosmer and Lemeshow Test (Sig.=0 .05) }\end{array}$ & -0.028 & 0.037 & 0.972 \\
\hline
\end{tabular}


The results showed that university students were more likely to accept AW education in their university curriculum than secondary students in schools. This result is in accordance with Mazas et al. (2013). Respondents from Italy as a Mediterranean country were prone to supporting AW educational programs in their curriculum. However, respondents in Sweden as a northern European country were less likely to accept the AW education. Women with a high level of subjective and objective knowledge levels were more concerned about the AW of the pig production systems, laboratory animals, and beef cattle. Respondents who believe that current AW regulation should be more restrictive showed greater willingness to accept AW education. Students who agree that medical experiments that use animals to improve human health were less likely to accept AW education.

\section{Conclusion}

The present study demonstrated clear evidence of two differentiated behaviors: university students in a southern EU country (Italy) exhibited significant agreement to the implementation of AW programs in their curriculum compared to a northern EU country (Sweden). Results showed that university students place higher values to support AW educational programs in their curriculum compared to secondary student's roles. Respondents with a high level of subjective and objective knowledge, women, and those who perceive that AW regulations should be more restrictive for the welfare of beef cattle, pigs, and laboratory animals, were more likely to accept AW education ( Herzog et al.,2009). Respondents who perceive the medical experiments that use animals to improve human health were less likely to accept AW education. Results highlight the importance of teaching AW concept as a comprehensive teaching tool at universities and schools' programs as it may constitute a starting point for a more sustainable society toward improving animal living conditions, mainly in the Mediterranean countries in secondary schools.

\section{Refrences}

Herzog, H. A., Betchart, N. S., \& Pittman, R. B. (2009). Gender, Sex Role Orientation, and Attitudes toward Animals. Anthrozoös, 4(3), 184-191. https://doi.org/10.2752/089279391787057170

Langford, C. L. (2006). Consumer Student or Citizen Student? The Clash of Campus Speech Codes and Free Speech Zones. Free Speech Yearbook, 43(1), 93-105. https://doi.org/10.1080/08997225.2006.10556331

Mazas, B., Fernández Manzanal, M. R., Zarza, F. J., \& María, G. A. (2013). Development and Validation of a Scale to Assess Students' Attitude towards Animal Welfare. International Journal of Science Education, 35(11), 1775-1799. https://doi.org/10.1080/09500693.2013.810354

Ronto, R., Ball, L., Pendergast, D., \& Harris, N. D. (2016). Food Literacy at Secondary Schools in Australia. Journal of School Health, 86(11), 823-831. https://doi.org/10.1111/josh.12440

Sandgren, E. P., Streiffer, R., Dykema, J., Assad, N., \& Moberg, J. (2020). Attitudes toward animals, and how species and purpose affect animal research justifiability, among undergraduate students and faculty. PLoS ONE, 15(5 May), 1-22. https://doi.org/10.1371/journal.pone.0233204

Weijden, J. J. A. Van Der, \& Verhave, S. I. P. S. (2013). Attitudes towards the use of Animals of Students enrolled in Animal Welfare and Laboratory Science courses in The Netherlands, (3516660), 1-22.

WHO_HPR_HEP_96.1.pdf. (n.d.). 